\title{
Real power loss reduction by arctic char algorithm
}

\author{
Lenin Kanagasabai \\ Department of EEE, Prasad V. Potluri Siddhartha Institute of Technology, India
}

\begin{tabular}{l} 
Article Info \\
\hline Article history: \\
Received Jan 3, 2020 \\
Revised Mar 4, 2020 \\
Accepted Jun 8, 2020 \\
\hline
\end{tabular}

\section{Keywords:}

Arctic char

Optimal reactive power

Transmission loss

\begin{abstract}
This work presents Arctic Char Algorithm (ACA) for solving optimal reactive power problem. In North America movement of Arctic char phenomenon is one among the twelve-monthly innate actions. Deeds of Arctic char have been imitated to design the algorithm. In stochastic mode solutions are initialized with one segment on every side of to the route ascendancy; particularly in between lower bound and upper bounds. Previous to the movement, Arctic char come to a decision about the passageway based on their perception. This implies stochastic mix up of control parameters to push the Arctic char groups (preliminary solution) in mutual pathway (evolutionary operators). Projected Arctic Char Algorithm (ACA) has been tested in standard IEEE 14,300 bus test system and simulation results show the projected algorithm reduced the real power loss extensively.
\end{abstract}

This is an open access article under the CC BY-SA license.

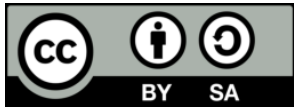

\section{Corresponding Author:}

Lenin Kanagasabai, Department of EEE,

Prasad V. Potluri Siddhartha Institute of Technology,

Kanuru, Vijayawada, Andhra Pradesh, 520007, India.

Email: gklenin@gmail.com

\section{INTRODUCTION}

Reactive power problem plays a key role in secure and economic operations of power system. Optimal reactive power problem has been solved by variety of types of methods [1-6]. Nevertheless, numerous scientific difficulties are found while solving problem due to an assortment of constraints. Evolutionary techniques [7-16] are applied to solve the reactive power problem, but the main problem is many algorithms get stuck in local optimal solution \& failed to balance the Exploration \& Exploitation during the search of global solution. This work presents Arctic Char Algorithm (ACA) for solving optimal reactive power problem. In North America movement of Arctic char phenomenon is one among the twelvemonthly innate actions. Through mountain streams millions of Arctic chars will move for spawning. During the movement starving bears, human fishers and waterfalls are generally significant threats they have to face. In this work deed of Arctic char has been imitated to design the algorithm. In stochastic mode solutions are initialized with one segment on every side of to the route ascendancy; particularly in between lower bound and upper bounds. Projected Arctic Char Algorithm (ACA) has been tested in standard IEEE 14,300 bus test system and simulation results show the projected algorithm reduced the real power loss extensively.

\section{PROBLEM FORMULATION}

Objective of the problem is to reduce the true power loss:

$$
\mathbf{F}=\mathbf{P}_{\mathrm{L}}=\sum_{\mathrm{k} \in \mathrm{Nbr}} \mathbf{g}_{\mathrm{k}}\left(\mathrm{V}_{\mathrm{i}}^{2}+\mathrm{V}_{\mathrm{j}}^{2}-2 \mathrm{~V}_{\mathrm{i}} \mathrm{V}_{\mathrm{j}} \cos \theta_{\mathrm{ij}}\right)
$$


Voltage deviation given as follows:

$F=P_{L}+\omega_{v} \times$ Voltage Deviation

Voltage deviation given by:

Voltage Deviation $=\sum_{\mathbf{i}=1}^{\mathrm{Npq}}\left|\mathbf{V}_{\mathbf{i}}-\mathbf{1}\right|$

Constraint (Equality)

$\mathbf{P}_{G}=\mathbf{P}_{D}+\mathbf{P}_{\mathbf{L}}$

Constraints (Inequality)

$$
\begin{aligned}
& \mathbf{P}_{\text {gslack }}^{\text {min }} \leq \mathbf{P}_{\text {gslack }} \leq \mathbf{P}_{\text {gslack }}^{\text {max }} \\
& \mathbf{Q}_{\mathrm{gi}}^{\text {min }} \leq \mathbf{Q}_{\mathrm{gi}} \leq \mathbf{Q}_{\mathrm{gi}}^{\mathrm{max}}, \mathbf{i} \in \mathbf{N}_{\mathrm{g}} \\
& \mathbf{V}_{\mathbf{i}}^{\text {min }} \leq \mathbf{V}_{\mathbf{i}} \leq \mathbf{V}_{\mathbf{i}}^{\text {max }}, \mathbf{i} \in \mathbf{N} \\
& \mathbf{T}_{\mathbf{i}}^{\text {min }} \leq \mathbf{T}_{\mathbf{i}} \leq \mathbf{T}_{\mathbf{i}}^{\text {max }}, \mathbf{i} \in \mathbf{N}_{\mathbf{T}} \\
& Q_{\mathrm{c}}^{\min } \leq \mathrm{Q}_{\mathrm{c}} \leq \mathrm{Q}_{\mathrm{C}}^{\max }, \mathrm{i} \in \mathrm{N}_{\mathrm{C}}
\end{aligned}
$$

\section{ARCTIC CHAR ALGORITHM}

In North America movement of Arctic char phenomenon is one among the twelve-monthly innate actions. Through mountain streams millions of Arctic chars will move for spawning. During the movement starving bears, human fishers and waterfalls are generally significant threats they have to face. In this work deed of Arctic char has been imitated to design the algorithm.

In stochastic mode solutions are initialized with one segment on every side of to the route ascendancy; particularly in between lower bound and upper bounds. Solutions are initialized arbitrary mode with reverence to the solution space.

$$
\text { Preliminary solution }=\text { lower bound }+ \text { random } *(\text { upper bound }- \text { lower bound })
$$

Previous to the movement, Arctic char come to a decision about the passageway based on their perception. This implies stochastic mix up of control parameters to push the Arctic char groups (preliminary solution) in mutual pathway (evolutionary operators).

$$
\text { Distribution of solution : }\left\{\begin{array}{c}
N_{A_{1}}=\left[\mu * A C_{S}\right] \\
N_{A_{2}}=A C_{S}-N_{A_{1}}
\end{array}\right.
$$

Where $N_{A_{1}}$ is the total number of Arctic char groups which pass through ocean and ponds, $N_{A_{2}}$ is the total number of Arctic char group transit through forest area and mountain valley, $A C_{S}$ is the total number of Arctic char groups which partake in the relocation and $\mu$ is Distribution factor is symbolizes the Arctic char intuition.

Crossing of ocean, lakes and ponds has been scientifically modeled as,

$$
\left\{\begin{array}{c}
Y_{N}=Y_{F}+\delta\left(t,\left(u b-Y_{F}\right)\right) \\
Y_{N}=Y_{F}+\delta\left(t,\left(y_{F}-\text { lower bound }\right)\right)
\end{array}\right.
$$

Where t symbolizes the present iteration number, $Y_{N}$ symbolize a new-fangled perceive region (fresh solution) and $Y_{F}$ shows the previous area of the explore convey (preceding solution). $\delta(y, z)$ is computed by,

$$
\delta(y, z)=z * \text { random } *\left(1-\frac{y}{T}\right)^{b}
$$



value 1

Where $T$ indicates maximum number of iterations, $b$ is an arbitrary number normally larger than

Chief hunters discover the regions with a satisfactory Arctic char concentration (solution fitness). Subsequent to that, they notify the engaged agent to make use of close by area to discover additional concentrated regions (solution with elevated fitness). This operation has been precisely defined by,

$$
Y_{R}=\beta *\left(Y_{M 1}-Y_{M 2}\right)+Y_{M 1}
$$

Where $\beta$ is a arbitrary number which span from 0 and 1 with consistent distribution, $Y_{R}$ stand for the freshly spotted solution by the engaged agent, $\mathrm{Y}_{\mathrm{M} 1}$ is the solution acquired by the primary key hunter and $\mathrm{Y}_{\mathrm{M} 2}$ is the solution acquired by the subsequent one.

Second operator simulates the bears hunt line of assault. Naturally they notify each other when they find an appropriate region. When they discover a region with superior Arctic char concentration, they notify to other bears. It expressed as,

$$
Y_{B}=\cos (\varphi) *\left(B T_{R}-C L_{R}\right)+B T_{R}
$$

Where $Y_{B}$ symbolizes the new-fangled spotted area, $\mathrm{BT}_{\mathrm{R}}$ is the most excellent accounted area by the hunting squad, $C L_{R}$ is the present area for which the bears have determined to execute the local exploitation and $\varphi$ is a capricious angle with a segment on every side of 0 to 360 degrees. $\cos (\varphi)$ articulate the bears to their objective.

End of the repositioning, stay alive Arctic char will get together in their mark for spawning. In Arctic char this normal event is replicated through a compilation stem. After Arctic char surpass through their passageway (operator's performance), the Arctic char subgroups (solutions) are composed in a exclusive stem. Solutions are extorted from mutual operators and make an exclusive population. At this condition, the proposed algorithm has reached the ending stage of the primary iteration.

Step1. Determine the population size, solution space, total number of variables, iterations

Step2. Regulate the Arctic char subgroups chaotically

Step3. Depending on migration $\mu$ passageway is chosen

Step4.Compute the fitness of hunted Arctic char

Step5. Arctic char used for spawn has been rumple together

Step6. If yes obtain the global solution or else go to step number 3.

\section{SIMULATION RESULTS}

At first in standard IEEE 14 bus system the validity of the proposed Arctic Char Algorithm (ACA) has been tested \& comparison results are presented in Table 1 .

Table 1. The validity of the proposed Arctic Char Algorithm (ACA)

\begin{tabular}{llll}
\hline Control variables & ABCO [17] & IABCO [17] & ACA \\
\hline V1 & 1.06 & 1.05 & 1.00 \\
V2 & 1.03 & 1.05 & 1.05 \\
V3 & 0.98 & 1.03 & 1.03 \\
V6 & 1.05 & 1.05 & 1.01 \\
V8 & 1.00 & 1.04 & 0.90 \\
Q9 & 0.139 & 0.132 & 0.100 \\
T56 & 0.979 & 0.960 & 0.900 \\
T47 & 0.950 & 0.950 & 0.900 \\
T49 & 1.014 & 1.007 & 1.000 \\
Ploss (MW) & 5.92892 & 5.50031 & 4.1652 \\
\hline
\end{tabular}

Then IEEE 300 bus system [18] is used as test system to validate the performance of the Arctic Char Algorithm (ACA). Table 2 shows the comparison of real power loss obtained after optimization.

Table 2. Comparison of real power loss

\begin{tabular}{lllll}
\hline Parameter & Method EGA [19] & Method EEA [19] & Method CSA [20] & ACA \\
\hline PLOSS (MW) & 646.2998 & 650.6027 & 635.8942 & 616.2596 \\
\hline
\end{tabular}




\section{CONCLUSION}

In this work Arctic Char Algorithm (ACA) successfully solved the optimal reactive power problem. Deeds of Arctic char have been imitated to design the algorithm. End of the repositioning, stay alive Arctic char will get together in their mark for spawning. In Arctic char this normal event is replicated through a compilation stem. After Arctic char surpass through their passageway (operator's performance), the Arctic char subgroups (solutions) are composed in a exclusive stem. Solutions are extorted from mutual operators and make an exclusive population. Projected Arctic Char Algorithm (ACA) has been tested in standard IEEE 14,300 bus test system and simulation results show the projected algorithm reduced the real power loss extensively.

\section{REFERENCES}

[1] K. Y. Lee., "Fuel-cost minimisation for both real and reactive-power dispatches," Proceedings Generation, Transmission and Distribution Conference, vol. 131, no. 3, pp. 85-93, 1984.

[2] N. I. Deeb., "An efficient technique for reactive power dispatch using a revised linear programming approach," Electric Power System Research, vol. 15, no. 2, pp. 121-134, 1998.

[3] M. R. Bjelogrlic, M. S. Calovic, B. S. Babic.,"Application of Newton's optimal power flow in voltage/reactive power control," IEEE Trans Power System, vol. 5, no. 4, pp. 1447-1454, 1990.

[4] S. Granville., "Optimal reactive dispatch through interior point methods," IEEE Transactions on Power System, vol. 9, no. 1, pp. 136-146, 1994.

[5] N. Grudinin., "Reactive power optimization using successive quadratic programming method," IEEE Transactions on Power System, vol. 13, no. 4, pp. 1219-1225, 1998.

[6] Wei Yan, J. Yu, D. C. Yu , K. Bhattarai., "A new optimal reactive power flow model in rectangular form and its solution by predictor corrector primal dual interior point method," IEEE Trans. Pwr. Syst.,vol. 21, no.1, pp. 61-67, 2006.

[7] Aparajita Mukherjee, Vivekananda Mukherjee, "Solution of optimal reactive power dispatch by chaotic krill herd algorithm," IET Gener. Transm. Distrib, vol. 9, vol. 15, pp. 2351-2362, 2015.

[8] Hu, Z., Wang, X. \& Taylor., "Stochastic optimal reactive power dispatch: Formulation and solution method," Electr. Power Energy Syst., vol. 32, pp. 615-621, 2010.

[9] Mahaletchumi A/P Morgan, Nor Rul Hasma Abdullah, Mohd Herwan Sulaiman,Mahfuzah Mustafa and Rosdiyana Samad, "Multi-objective evolutionary programming (MOEP) using mutation based on adaptive mutation operator (AMO) applied for optimal reactive power dispatch," ARPN Journal of Engineering and Applied Sciences, vol. 11, no. 14,2016

[10] Pandiarajan, K. \& Babulal, C. K., “ Fuzzy harmony search algorithm based optimal power flow for power system security enhancement,” International Journal Electric Power Energy Syst., vol. 78, pp. 72-79, 2016.

[11] Mahaletchumi Morgan, Nor Rul Hasma Abdullah, Mohd Herwan Sulaiman, Mahfuzah Mustafa, Rosdiyana Samad, "Benchmark studies on optimal reactive power dispatch (ORPD) based multi-objective evolutionary programming (MOEP) using mutation based on adaptive mutation adapter (AMO) and polynomial mutation operator (PMO)," Journal of Electrical Systems, vol. 12, no. 1, pp. 121-132, 2016.

[12] Rebecca Ng Shin Mei, Mohd Herwan Sulaiman, Zuriani Mustaffa, "Ant lion optimizer for optimal reactive power dispatch solution,” Journal of Electrical Systems, Special Issue AMPE2015, pp. 68-74, 2016.

[13] Gagliano A., Nocera F., "Analysis of the performances of electric energy storage in residential applications," International Journal of Heat and Technology, vol. 35, Special Issue 1, pp. S41-S48, 2017.

[14] Caldera M., Ungaro P., Cammarata G., Puglisi G., "Survey-based analysis of the electrical energy demand in Italian households," Mathematical Modelling of Engineering Problems, vol. 5, no. 3, pp. 217-224, 2018.

[15] Puris.A, Bello, R., Molina, D. \& Herrera, F. "Variable mesh optimization for continuous optimization problems," Soft Computing, vol. 16, no. 3, pp. 511-523, 2012.

[16] Price.K, R. M. Storn, and J. A. Lampinen, Differential evolution: A practical approach to global optimization, Springer, 2006.

[17] Chandragupta Mauryan Kuppamuthu Sivalingam, Subramanian Ramachandran, Purrnimaa Shiva Sakthi Rajamani, "Reactive power optimization in a power system network through metaheuristic algorithms," Turkish Journal of Electrical Engineering and Computer Sciences, vol. 25, no. 6, pp. 4615-4623, 2017.

[18] IEEE, "The IEEE-test systems" Retreived from: http://www.ee.washington.edu/trsearch/pstca/, 1993.

[19] S.S. Reddy, et al., "Faster evolutionary algorithm based optimal power flow using incremental variables," Electrical Power and Energy Systems, vol. 54, pp. 198-210, 2014.

[20] S. Surender Reddy, "Optimal reactive power scheduling using cuckoo search algorithm," International Journal of Electrical and Computer Engineering, vol. 7, no. 5, pp. 2349-2356, 2017. 